\title{
Unmet basic needs negatively affect health-related quality of life in people aging with HIV: results from the Positive Spaces, Healthy Places study
}

\author{
Phan Sok ${ }^{1 *}$ (1), Sandra Gardner ${ }^{2}$, Tsegaye Bekele ${ }^{3}$, Jason Globerman ${ }^{4}$, Mary V. Seeman ${ }^{1}$, Saara Greene ${ }^{5,9}$, \\ Michael Sobota ${ }^{6}$, Jay J. Koornstra ${ }^{7}$, LaVerne Monette ${ }^{8^{\wedge}}$, Keith Hambly ${ }^{9}$, Stephen W. Hwang ${ }^{10}$, James Watson ${ }^{10}$, \\ Glen Walker ${ }^{11}$, Sean B. Rourke ${ }^{10,12}$ and The Positive Spaces, Healthy Places Team
}

\begin{abstract}
Background: Basic needs (e.g., food security and stable housing) are important determinants of health and well-being, yet their impact on health-related quality of life (HRQOL) in the context of HIV and aging has not been systematically investigated.

Methods: Multiple linear regression models examined the relationship between unmet basic needs, and physical and mental HRQoL by age strata (20-34, 35-49 and 50+) in a cross-sectional sample of 496 people living with HIV in Ontario, Canada.

Results: An overwhelming majority of participants (87\%) reported unmet needs related to food, clothing or housing. The prevalence of unmet basic needs in the two older groups appeared to be lower than among younger participants, but the difference did not reach statistical significance. The presence of unmet basic needs predicted substantially lower mean physical health and mental health summary scores in the two oldest groups. Notably, age moderated the influence of unmet basic needs on HRQoL.
\end{abstract}

Conclusions: The availability and accessibility of food security, appropriate clothing and stable housing for people living with HIV who are aging need to become a higher priority for program planners and decision makers.

Keywords: HIV, Aging, Basic needs, Health-related quality of life

\section{Background}

Basic needs (e.g., food security and stable/affordable housing) are important determinants of health and well-being among people living with HIV. A study by Cunningham et al. [1] showed that when basic needs (food, clothing and housing) were unmet, more than one-third of HIVpositive people in the United States did not keep their medical appointments. Two other studies reported that unmet basic needs with respect to food, clothing and

\footnotetext{
* Correspondence: phan.sok@gmail.com

Sean B. Rourke is senior author.

Deceased

${ }^{1}$ Institute of Medical-Science, University of Toronto, Toronto, Canada

Full list of author information is available at the end of the article
}

housing constituted the most important predictors of poor physical health and mental health in HIV-infected homeless women [2] and men [3]. A recent study showed that men living with HIV receiving community mental health supports had greater unmet health needs than HIVnegative men who did receive such supports [4].

Literature reviews of adults with HIV indicate that they face many challenges associated with health and wellbeing. These challenges encompass socioeconomics [5, 6], depression [7], housing [8] and food security $[9,10]$. Older adults with HIV experience similar challenges [11-14]. In addition, they face issues of sexuality $[15,16]$, high risk behaviours [17, 18], premature age-related comorbidities [19], early frailty [20], poor physical function [21] and shortened life expectancy [22]. These added burdens 
contribute to negative health-related quality of life (HRQoL). We also know that the natural age process negatively impacts on physical health in the general population over age 65 [23] and on several dimensional subscales of HRQoL in people living with HIV [24]. What is still not clear is the degree to which unmet basic needs may impact HRQoL in the context of HIV and aging. This in critical as the effectiveness of combination antiretroviral therapy now allows people living with HIV to reach older age.

The objective of this study was to determine the degree to which unmet basic needs are associated with physical and mental HRQoL; specifically, whether these associations vary with increasing age. We hypothesized that unmet basic needs related to food, clothing or housing stability/affordability would significantly and negatively impact physical health and mental health quality of life among people living with HIV, especially with increasing age.

\section{Methods}

\section{Study design and data}

This cross-sectional study used baseline data (2006) from the Positive Spaces, Healthy Places (PSHP) study. The PSHP study is a five-year observational cohort of 602 individuals living with HIV in Ontario, Canada. It was designed to evaluate the effects of housing on health. We included 496 participants in the current study because 106 (17.6\%) study participants were excluded due to missing data on one or more socioeconomic or clinical data points. Thirty-seven had no data on basic needs. We note that the overall mean physical health and mental health summary scores did not differ significantly between excluded and included participants. The PSHP study is supported by grants from the Canadian Institutes of Health Research (CBR-75568 and CBR-94036), the Ontario Ministry of Health and Long-Term Care, the Ontario AIDS Network, the Wellesley Institute and the Ontario HIV Treatment Network (CCB115).

\section{Procedures}

To be eligible in the PSHP study, participants had to be HIV positive, 18-years or older, able to provide informed consent and reside in Ontario. To ensure people with unstable housing situations were included, participants were recruited from community-based AIDS service agencies, shelters, agencies serving women, Indigenous organizations, supportive housing agencies, transitional housing providers, agencies providing HIV programs and services for harder-to-reach populations (e.g., injection drug users, homeless people and those with unstable housing). All survey data were collected via face-to-face interviews conducted by trained peer researchers living with HIV. A 40 CAD honorarium was provided for participating. The study was approved by the Research Ethics Board at the University of Toronto (REB\#25710). Additional details and descriptions of the PSHP cohort are available elsewhere [8].

\section{Measures \\ Conceptualizing basic needs}

We conceptualized basic needs as those essential to daily life. We evaluated basic needs in three steps. Step 1, we looked at four items on the 62-item PSHP questionnaire relating to food, clothing, housing-related costs and risk of homelessness. For food, the participants were asked "In the last 12 months, have you ever experienced difficulty in buying enough food?" The response was "yes or no" (Question 60a). For clothing, the participants were asked: "In the last 12 months, have you ever experienced difficulty in buying sufficient clothing for yourself or your dependent(s)?" The response was "yes or no" (Question 61a). For housing-related costs, the participants were asked: "Considering your income, how difficult is it for you to meet your monthly housing-related costs?" The responses were "very difficult, fairly difficult, very little difficult or not at all difficult". We, however, collapsed "very difficult and fairly difficult" into "difficulty" and collapsed "very little difficulty and not at all difficult" into "non-difficulty" (Question 23). For risk of homelessness, the participants were asked: "How much do you pay in rent/mortgage every month?" (Question 57). We adapted the Canadian Definition of Homelessness [25] that defined the risk of homelessness as occurring when a person is spending $30 \%$ or more of his or her income (before taxes) on rent or mortgage. A formula was created and applied to each participant in the sample ${ }^{1}$ : $R H=\frac{i n c}{\text { mor }}$. In step 2, we differentiated between met (coding $=0$ ) and unmet (coding =1). Thus, unmet basic needs were defined as responding either yes to food, or yes to clothing, or difficulty to housing-related costs or being at risk of homelessness. Finally, step 3, we tested for the internal consistency of the four items [26] Cronbach's alpha was somewhat low, 0.58 , but, because we tested only four items and the value of Cronbach's alpha is affected by the number of items tested [27]. We felt that this was adequate for our purpose.

\section{Outcome variables}

We derived physical health and mental health summary scores from the 35-item Medical Outcomes Study HIV Health Survey (MOS-HIV) [28]. The MOS-HIV has been criticized [29] but is, nevertheless, considered to be a robust tool for measuring HRQoL in people living with HIV and has been translated into 19 languages [30]. The instrument includes 10 dimensions of health: general health (5 items), physical functioning (6 items), role functioning (2 items), social functioning (2 items), 
energy (4 items), mental health (5 items), health distress (4 items), cognitive functioning (4 items), pain (2 items) and quality of life (1 item). All scales were linearly transformed into a 0 (worst health) to 100 (best health) scale and were then converted into $z$-scores in order to standardize them to the reference population of patients with HIV/AIDS. We then computed and created standardized scores for physical health and mental health summary scores as per instructions of the survey developers [31]. In this study, the 35-item MOS-HIV had a Cronbach's alpha of 0.90. Prior studies have suggested that HRQoL summary scores are reproducible, reliable and valid tools for measuring HIV patient functioning and well-being [32].

\section{Age groups}

We categorized participants into three age groups: young (20-34 years), middle- aged (35-49 years) and old (50+ years). We used the cut-off of age 50 for the beginning of old age as this cut-off is considered a clinically important threshold in this population [33].

\section{Variables}

Demographic variables included gender (female vs. male), ethnicity (Caucasian vs. other) and sexual orientation (heterosexual vs. other). Socioeconomic status variables included educational level (high school degree or above vs. no high school degree), employment status (employed vs. unemployed; unemployed included retired/ disabled) and personal gross income (high vs. low income; low income meant below the cut-off of $1150 \mathrm{CAD} /$ month, the median income of this study sample). Social factor variables included living arrangements (living with someone vs. living alone) and social support (high vs. low support; low support meant below the cut-off of 43, the median scores of this study sample). Social support scores were derived from the 19-item Medical Outcomes Study Social Support Survey [34]. HIV clinical marker variables included previous diagnosis of AIDS (absence vs. presence), CD4 T-cell count (above vs. below 200 cells $/ \mathrm{mL}$ ), years since HIV diagnosis and years since starting antiretroviral therapy. All variables were self-reported.

\section{Statistical analysis \\ Descriptive analyses}

A descriptive analysis of sample characteristics was performed across three age strata. For categorical comparisons, a Chi-square $\left(x^{2}\right)$ or Fisher's exact tests was used. For variance comparisons, a least square means analysis for unbalanced samples was applied [35].

\section{Modeling approaches}

To better understand the influence of the hypothesized relationships at different age levels $[36,37]$, we separately performed a series of multivariable linear regressions for the physical health and the mental health summary models. The three age groups were entered as dummy variables when performing univariate and multivariate analyses. For each model, covariates were entered as blocks in the following order: demographics (step 1), socioeconomic status (step 2), social factors (step 3), HIV clinical markers (step 4) and unmet basic needs (step 5). To understand the effect of unmet basic needs across subject groups [37], we tested the interaction terms (step 6), which were unmet basic needs $x$ the middle-aged group, and unmet basic needs $\mathrm{x}$ the older group. We assessed interaction effects via the visuographic method. We eliminated co-linearity, using the variance inflation factor and eigenvalue [35]. A two-sided $p$-value of less than 0.05 was used for statistically significant variables throughout. All analyses were performed using SAS software 9.3 (Cary, North Carolina, USA).

\section{Results}

Sample characteristics

Mean age (SD) of the sample was 43.7 (8.4) years, [range 20-70] (Table 1). A majority of respondents (80.4\%) in our sample reported being unemployed. Over half (52. $0 \%)$ had been previously diagnosed with AIDS. The sample mean (SD) for physical health summary scores was 42.6 (10.8) [range14.9-64.6], and the sample mean (SD) for health summary scores was 43.4 (11.9) [range 8.7-68. 6]. Role functioning scored lowest, 40.9 (10.4). The highest score was on the pain subscale, 47.8 (9.7).

Our sample significantly differed among age categories with respect to gender, sexual orientation and ethnicity. Gay or bisexual male participants were older than female same sex or heterosexual participants. There were no significant differences across educational level, employment status, gross income or social support. Compared to the two younger groups, the older group had lower mean physical health summary scores $(p<0.001)$.

\section{Basic needs}

Over $85 \%$ of the respondents self-reported at least one unmet basic need. Substantially fewer individuals in the middle-aged and old age groups reported unmet basic needs than did those in the youngest group (Fig. 1) although the results were not statistically significant $(p=0.19)$. When analyzing basic needs across demographics, the prevalence of unmet basic needs did not differ by gender (men, $85.5 \%$ vs. women, $90.7 \%$ ), ethnic group (Caucasians, $88.4 \%$ vs. other, $86.1 \%$ ) or sexual preference (non-heterosexuals, $85.3 \%$ vs. other, 89 . $4 \%)$. Participants without a high school degree and those with no job at the time of interview were more likely to report unmet basic needs than their peers (93.1\% vs. 85 . $0 \%, p=0.03$ or $88.7 \%$ vs. $78.3 \%, p=0.007$; respectively). 
Table 1 Sample characteristics by age group $(N=496)$

\begin{tabular}{|c|c|c|c|c|c|}
\hline \multirow[t]{4}{*}{ Variables } & \multirow[b]{2}{*}{ All sample } & \multicolumn{3}{|c|}{ Age groups } & \multirow[t]{4}{*}{$p^{a}$} \\
\hline & & $20-34$ & $35-49$ & $\geq 50$ & \\
\hline & $N=496$ & $n=70$ & $n=310$ & $n=116$ & \\
\hline & $\%$ & $\%$ & $\%$ & $\%$ & \\
\hline \multicolumn{6}{|l|}{ Demographic variables } \\
\hline Male & 76.2 & 52.9 & 79.4 & 81.9 & $<0.001$ \\
\hline Caucasian & 75.6 & 65.7 & 73.6 & 87.1 & 0.002 \\
\hline Heterosexual & 34.1 & 54.3 & 32.9 & 27.6 & $<0.001$ \\
\hline \multicolumn{6}{|l|}{ Economic variables } \\
\hline No high school degree & 20.6 & 25.7 & 21.6 & 14.7 & 0.15 \\
\hline Unemployed & 80.4 & 74.3 & 79.7 & 86.2 & 0.12 \\
\hline Low income (<1150 CAD/month) & 51.4 & 61.4 & 49.0 & 51.7 & 0.17 \\
\hline \multicolumn{6}{|l|}{ Social variables } \\
\hline Low support (MOS-SSS < 43) & 51.0 & 51.4 & 48.7 & 56.9 & 0.32 \\
\hline Living alone & 50.0 & 22.9 & 50.7 & 64.7 & $<0.001$ \\
\hline \multicolumn{6}{|l|}{ Clinical variables } \\
\hline A history of AIDS diagnosis & 52.0 & 24.3 & 56.1 & 57.8 & $<0.001$ \\
\hline CD4 count $<200$ cells $/ \mathrm{mL}(n=412)$ & 60.9 & 28.9 & 65.5 & 65.7 & $<0.001$ \\
\hline Years since HIV diagnosis (mean, SD) & $11.4(6.5)$ & $5.3(4.5)$ & $11.7(6.0)$ & $14.3(6.4)$ & $<0.001$ \\
\hline Years since starting ART $(n=379$, mean, SD) & $8.1(5.5)$ & $4.0(3.6)$ & $7.9(5.3)$ & $9.7(5.6)$ & $<0.001$ \\
\hline \multicolumn{6}{|l|}{ Health-related quality of life } \\
\hline Physical health summary scores (mean, SD) & $42.6(10.8)$ & $47.5(9.0)$ & $42.7(11.0)$ & $39.5(10.2)$ & $<0.001$ \\
\hline Mental health summary scores (mean, SD) & $43.4(11.9)$ & $42.4(12.5)$ & $43.6(11.9)$ & $43.5(11.6)$ & 0.72 \\
\hline
\end{tabular}

Among those with personal gross income below 1150 $\mathrm{CAD} /$ month (51.4\%), the two older groups were less likely than the youngest group to report unmet needs $(p=0.08)$. Among those who were unemployed, the two older groups were less likely to report unmet needs than the youngest group, but the results did not quite reach statistical significance. Among those who had not finished high school (20.6\%), the oldest group (76\%) was less likely

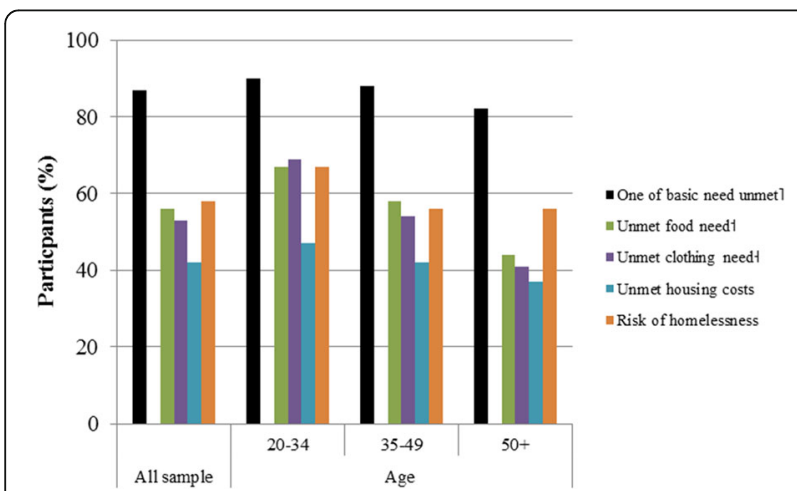

Fig. 1 Proportions of each unmet basic need by age group $(N=496)$ Chi-Square tests: 1 Basic need unmet $(p=0.19) ; 1$ Unmet food need $(p=0.001) ; \uparrow$ Unmet clothing need $(p=0.005)$ to report unmet needs than the two younger groups $(p=0.01$, Fisher's exact).

\section{Univariate analyses of $H R Q O L$}

The presence of unmet basic needs was associated with both poorer physical health and poorer mental health summary scores $(\beta=-6.4, p<0.001$ and $\beta=-8.2, p<0.001$, respectively, Table 2 ). The middle-aged group, the older group, unemployed individuals, Caucasians, those with a previous diagnosis of AIDS and with a longer duration since HIV diagnosis, all had significantly lower physical health summary scores. Being female, unemployed, heterosexual, having low social support and a personal income below $1150 \mathrm{CAD} /$ month were all significantly associated with lower mental health summary scores.

\section{Multivariate analyses of $\mathrm{HRQOL}$}

We employed a series of hierarchical multiple regression analyses to evaluate the effect of unmet basic needs on physical health summary scores (Table 3). We entered the following variables in order: demographics (step 1), socioeconomic status (step 2), social factors (step 3) and HIV clinical markers (step 4). After entering unmet basic needs 
Table 2 Univariate regression analyses of physical health and mental health summary scores. $(N=496)$

\begin{tabular}{|c|c|c|c|c|c|c|}
\hline \multirow[t]{2}{*}{ Variables } & \multicolumn{3}{|c|}{ Physical health summary } & \multicolumn{3}{|c|}{ Mental health summary } \\
\hline & $\beta$ & $(95 \% \mathrm{Cl})$ & $p$ & $\beta$ & $(95 \% \mathrm{Cl})$ & $p$ \\
\hline \multicolumn{7}{|l|}{ Demographic variables } \\
\hline Age $20-34$ & Ref. & & & Ref. & & \\
\hline Age 35-49 & -4.80 & $(-7.54,-2.06)$ & $<0.001$ & 1.28 & $(-1.81,4.38)$ & 0.415 \\
\hline Age $50+$ & -7.97 & $(-11.1,-4.83)$ & $<0.001$ & 1.14 & $(-2.40,4.68)$ & 0.528 \\
\hline Female & -1.39 & $(-3.63,0.84)$ & 0.222 & -4.08 & $(-6.52,-1.64)$ & 0.001 \\
\hline Caucasian & -2.82 & $(-5.02,-0.61)$ & 0.012 & -0.78 & $(-3.23,1.66)$ & 0.529 \\
\hline Heterosexual & -1.13 & $(-3.14,0.88)$ & 0.270 & -3.03 & $(-5.23,-0.83)$ & 0.007 \\
\hline \multicolumn{7}{|l|}{ Economic variables } \\
\hline No high school degreedegree & -2.76 & $(-5.11,-0.42)$ & 0.021 & -3.49 & $(-6.08,-0.91)$ & 0.008 \\
\hline Unemployed & -7.44 & $(-9.75,-5.13)$ & $<0.001$ & -6.23 & $(-8.82,-3.64)$ & $<0.001$ \\
\hline Low income (<1150 CAD/month) & -1.15 & $(-3.06,0.75)$ & 0.235 & -3.23 & $(-5.31,-1.14)$ & 0.003 \\
\hline \multicolumn{7}{|l|}{ Social variables } \\
\hline Low support (MOS-SSS < 43) & -3.39 & $(-5.27,-1.51)$ & $<0.001$ & -6.96 & $(-8.96,-4.95)$ & $<0.001$ \\
\hline Living alone & -2.10 & $(-4.0,-0.20)$ & 0.030 & -1.98 & $(-4.07,0.11)$ & 0.064 \\
\hline \multicolumn{7}{|l|}{ Clinical variables } \\
\hline A history of AIDS diagnosis & -5.07 & $(-6.92,-3.22)$ & $<0.001$ & -3.09 & $(-5.18,-1.01)$ & 0.004 \\
\hline CD4 count $<200$ cells/mL $[n=412]$ & -2.48 & $(-4.58,-0.38)$ & 0.021 & 0.56 & $(-1.82,2.93)$ & 0.646 \\
\hline Years since HIV diagnosis & -0.15 & $(-0.29,-0.00)$ & 0.045 & 0.22 & $(0.06,0.38)$ & 0.007 \\
\hline Years since starting ART [ $n=379]$ & -0.20 & $(-0.40,-0.01)$ & 0.041 & 0.21 & $(-0.01,-0.43)$ & 0.063 \\
\hline \multicolumn{7}{|l|}{ Basic needs variable } \\
\hline Unmet basic needs & $-6.58^{\mathrm{a}}$ & $(-9.31,-3.86)$ & $<0.001$ & $-8.24^{b}$ & $(-11.25,-5.24)$ & $<0.001$ \\
\hline
\end{tabular}

Bold values are significant of $p<0.05$. ${ }^{a}$ Estimates ( $\beta$ ) unmet needs: food $=-3.95$, clothing $=-3.81$, housing costs $=-4.23$ (all, $p<0.001$ ), risk of homelessness $=$ -1.66 ( $p>0.05$ ). ${ }^{b}$ Estimates $(\beta)$ unmet needs: food $=-5.9$, clothing $=-5.4$, housing costs $=-5.43$ or risk of homelessness $=-3.64$ (all, $p<0.001$ ), Cl: Confidence Interval; MOS-SSS: Medical Outcomes Study Social Support Survey; ART: antiretroviral therapy

(step 5), the proportion of variance increased from 19.2\% to $22.1 \%$. After entering the two interaction terms (step 6), the amount of variance increased significantly to $23.5 \%$.

To evaluate the effect of unmet basic needs on mental health summary scores, we employed a series of hierarchical multiple regression analyses as shown in Table 4. We repeated step 1 to 4 as we did previously. In step 5, after adding the unmet basic needs, the variance increased significantly from $19.2 \%$ to $22.4 \%$. In step 6 , after adding both interaction terms as we did before, the amount of variance increased significantly to $24.1 \%$.

\section{Interaction terms}

We noted that unmet needs lowered physical health scores to a greater degree in the oldest group than they did in the middle-aged group (Fig. 2a). On mental health summary scores, the slope was a bit steeper in the oldest group compared to the middle-aged group as a result of the effect of unmet needs (Fig. 2b).

\section{Discussion}

Our primary hypothesis was that unmet basic needs would be significantly and negatively associated with lower physical health or mental health quality of life summary scores even after controlling for potential confounders. Also, we predicted that the impact of unmet basic needs would vary across age groups, and increase with age. We found a very high prevalence of unmet basic needs in our HIV study participants in Ontario, Canada. We noted that age moderated the influence of unmet basic needs on HRQoL.

Our conceptualization of unmet basic needs as a predictor of poor health and well-being is consistent with previous studies related to basic subsistence needs in HIV-infected adults [1-3]. The very high prevalence of unmet basic needs among people living with HIV in our study may have been magnified by the nature of our sample, which was purposefully recruited to represent a population with unstable housing. This notwithstanding, it is important to note that, when examining the influence of demographics or socioeconomic status, the proportion of unmet basic needs did not differ by gender, race or sexual orientation. This suggests that problems meeting basic needs is an across-the-board challenge for people living with HIV in our province. 
Table 3 Hierarchical multivariate regression models for physical health summary scores. $(N=496)$

\begin{tabular}{|c|c|c|c|c|c|c|}
\hline & $\begin{array}{l}\text { Step } 1 \\
\beta\end{array}$ & $\begin{array}{l}\text { Step } 2 \\
\beta\end{array}$ & $\begin{array}{l}\text { Step } 3 \\
\beta\end{array}$ & $\begin{array}{l}\text { Step } 4 \\
\beta\end{array}$ & $\begin{array}{l}\text { Step } 5 \\
\beta^{*}\end{array}$ & $\begin{array}{l}\text { Step } 6 \\
\beta\end{array}$ \\
\hline Intercept & $51.48^{\mathrm{a}}$ & $56.83^{\mathrm{a}}$ & $58.38^{\mathrm{a}}$ & $58.67^{\mathrm{a}}$ & $63.10^{\mathrm{a}}$ & $54.10^{\mathrm{a}}$ \\
\hline \multicolumn{7}{|l|}{ Block 1} \\
\hline \multicolumn{7}{|l|}{ Age group } \\
\hline 20-34 (Ref.) & 1 & 1 & 1 & 1 & 1 & 1 \\
\hline $35-49$ & $-5.52^{\mathrm{a}}$ & $-5.12^{\mathrm{a}}$ & $-5.21^{\mathrm{a}}$ & $-4.28^{b}$ & $-4.18^{b}$ & 5.33 \\
\hline $50+$ & $-8.39^{a}$ & $-7.63^{\mathrm{a}}$ & $-7.46^{\mathrm{a}}$ & $-6.58^{\mathrm{a}}$ & $-6.80^{\mathrm{a}}$ & 4.95 \\
\hline Female & -2.32 & $-2.65^{d}$ & $-3.06^{c}$ & $-3.08^{c}$ & $-2.88^{c}$ & $-2.95^{c}$ \\
\hline Caucasian & $-3.14^{b}$ & $-3.31^{b}$ & $-3.60^{b}$ & $-3.43^{b}$ & $-3.37^{b}$ & $-3.43^{b}$ \\
\hline Heterosexual & -1.57 & -1.0 & -0.62 & -0.72 & -0.79 & -0.72 \\
\hline \multicolumn{7}{|l|}{ Block 2} \\
\hline No high school degree & & -1.79 & $-2.06^{\mathrm{d}}$ & $-1.90^{\mathrm{d}}$ & -1.54 & -1.62 \\
\hline Unemployed & & $-6.91^{a}$ & $-6.60^{\mathrm{a}}$ & $-6.04^{a}$ & $-5.46^{\mathrm{a}}$ & $-5.50^{\mathrm{a}}$ \\
\hline Low income (<1150 CAD/month) & & 0.30 & 0.49 & 0.43 & 0.39 & 0.29 \\
\hline \multicolumn{7}{|l|}{ Block 3} \\
\hline Low support (MOS-SSS < 43) & & & $-3.17^{a}$ & $-3.16^{\mathrm{a}}$ & $-2.94^{\mathrm{b}}$ & $-2.95^{\mathrm{b}}$ \\
\hline Living alone & & & -0.03 & 0.02 & -0.19 & -0.26 \\
\hline \multicolumn{7}{|l|}{ Block 4} \\
\hline A history of AIDS diagnosis & & & & $-3.64^{\mathrm{a}}$ & $-3.64^{\mathrm{a}}$ & $-3.59^{\mathrm{a}}$ \\
\hline Years since HIV diagnosis & & & & 0.02 & -0.002 & -0.005 \\
\hline \multicolumn{7}{|l|}{ Block 5} \\
\hline Unmet basic needs & & & & & $-5.53^{\mathrm{a}^{*}}$ & 4.67 \\
\hline \multicolumn{7}{|l|}{ Block 6} \\
\hline Unmet basic needs $X$ age $35-49$ & & & & & & $-10.56^{c}$ \\
\hline Unmet basic needs $X$ age $50+$ & & & & & & $-13.22^{b}$ \\
\hline$R^{2}$ & 0.073 & 0.144 & 0.165 & 0.192 & 0.221 & 0.235 \\
\hline F Change & $7.725^{\mathrm{a}}$ & $13.537^{\mathrm{a}}$ & $6.110^{b}$ & $7.880^{\mathrm{a}}$ & $18.049^{\mathrm{a}}$ & $4.423^{b}$ \\
\hline F Test & $7.73^{\mathrm{a}}$ & $10.28^{\mathrm{a}}$ & $9.61^{\mathrm{a}}$ & $9.55^{\mathrm{a}}$ & $10.52^{\mathrm{a}}$ & $9.83^{\mathrm{a}}$ \\
\hline
\end{tabular}

${ }^{\mathrm{a}} p<0.001,{ }^{\mathrm{b}} p<0.01,{ }^{c} p<0.05,{ }^{\mathrm{d}} p$ approached the significance $<0.05$. CD4 count $<200$ cells $/ \mathrm{mL}$ was not included because it was insignificantly associated with physical health summary scores $(p=0.566)$. Years since starting ART was excluded because of co-linearity with the variable, years since HIV diagnosis. *Further multivariable linear regression models were performed for each basic need, estimated coefficient ( $\beta$ ) unmet needs: food $=-3.65$, clothing $=-3.72$, housing cost $=-3.67$ (all, $p<0.001$ ) or risk of homelessness $=-1.04(p>0.05)$

The fact that there was a trend (not quite reaching statistical significance) for the prevalence of unmet basic needs in the two older groups to be lower than that in the younger participants, can perhaps be explained by the demographic and socioeconomic profiles of the two older groups, which were very similar to study populations described in other reports [15, 38, 39]. Our two older groups were well-educated and enjoyed relatively high personal incomes. The high rate of unemployment in this older population was probably the result of their chronic illness. However, participants belonging to the two older groups who reported lower socioeconomic status had a significantly lower prevalence of unmet basic needs than the youngest group. As Joyce et al. [39] noted, older white and gay men with HIV enjoy greater financial stability than their younger peers. Previous studies have shown that older individuals with HIV have better adherence [40] and achieve a more rapid virologic response to antiretroviral treatments than younger peers [41]. Older adults with HIV, compared to younger adults, also tend to show greater resilience to stress [42, 43]. This may increase physical, emotional and functional well-being, a sign of successful aging [44, 45].

We found that age moderated the main effect of unmet basic needs on both physical health and mental health summaries. The effect of unmet basic needs on mean physical health summary scores was much greater in the oldest group than in the middle-aged group. In contrast, the effect of unmet basic needs on mean mental health summary scores was essentially similar. These 
Table 4 Hierarchical multivariate regression models for mental health summary scores. $(N=496)$

\begin{tabular}{|c|c|c|c|c|c|c|}
\hline & Step 1 & Step 2 & Step 3 & Step 4 & Step 5 & Step 6 \\
\hline & $\beta$ & $\beta$ & $\beta$ & $\beta$ & $\beta$ & $\beta$ \\
\hline Intercept & $46.40^{\mathrm{a}}$ & $51.99^{a}$ & $55.39^{\mathrm{a}}$ & $54.32^{\mathrm{a}}$ & $59.46^{\mathrm{a}}$ & $47.94^{\mathrm{a}}$ \\
\hline \multicolumn{7}{|l|}{ Block 1} \\
\hline \multicolumn{7}{|l|}{ Age group } \\
\hline 20-34 (Ref.) & 0 & 0 & 0 & 0 & 0 & 0 \\
\hline $35-49$ & 0.18 & 0.26 & 0.14 & -0.39 & -0.27 & $12.66^{\mathrm{b}}$ \\
\hline $50+$ & 0.18 & 0.61 & 1.09 & -0.04 & -0.24 & $13.23^{b}$ \\
\hline Female & $-3.49^{c}$ & $-3.73^{c}$ & $-4.67^{b}$ & $-4.61^{b}$ & $-4.38^{\mathrm{b}}$ & $-4.47^{b}$ \\
\hline Caucasian & $-2.29^{d}$ & $-2.51^{d}$ & $-3.12^{c}$ & $-3.20^{\mathrm{b}}$ & $-3.13^{b}$ & $-3.23^{b}$ \\
\hline Heterosexual & -1.63 & -1.13 & -0.41 & 0.06 & -0.03 & 0.06 \\
\hline \multicolumn{7}{|l|}{ Block 2} \\
\hline No high school degree & & -1.59 & $-2.17^{d}$ & $-2.30^{\mathrm{d}}$ & -1.87 & -1.89 \\
\hline Unemployed & & $-5.56^{\mathrm{a}}$ & $-4.87^{\mathrm{a}}$ & $-4.55^{\mathrm{a}}$ & $-3.87^{b}$ & $-3.91^{b}$ \\
\hline Low income (<1150 CAD/month) & & -1.74 & -1.26 & -1.14 & -1.19 & -1.30 \\
\hline \multicolumn{7}{|l|}{ Block 3} \\
\hline Low social support (MOS-SSS < 43) & & & $-6.85^{\mathrm{a}}$ & $-6.91^{\mathrm{a}}$ & $-6.65^{a}$ & $-6.66^{a}$ \\
\hline Living alone & & & -0.37 & -0.20 & -0.48 & -0.53 \\
\hline \multicolumn{7}{|l|}{ Block 4} \\
\hline A history of AIDS diagnosis & & & & $-2.98^{\mathrm{b}}$ & $-2.98^{b}$ & $-2.90^{\mathrm{b}}$ \\
\hline Years since HIV diagnosis & & & & $0.24^{\mathrm{b}}$ & $0.22^{c}$ & $0.21^{c}$ \\
\hline \multicolumn{7}{|l|}{ Block 5} \\
\hline Unmet basic needs & & & & & $-6.40^{\mathrm{a}^{*}}$ & 6.60 \\
\hline \multicolumn{7}{|l|}{ Block 6} \\
\hline Unmet basic needs $X$ age $35-49$ & & & & & & $-14.39^{b}$ \\
\hline Unmet basic needs $X$ age $50+$ & & & & & & $-15.09^{b}$ \\
\hline$R^{2}$ & 0.029 & 0.083 & 0.165 & 0.192 & 0.224 & 0.241 \\
\hline FChange & $2.889^{b}$ & $9.578^{a}$ & $23.922^{\mathrm{a}}$ & $8.050^{\mathrm{a}}$ & $19.978^{\mathrm{a}}$ & $5.410^{k}$ \\
\hline F Test & $2.89^{b}$ & $5.49^{\mathrm{a}}$ & $9.59^{\mathrm{a}}$ & $9.57^{\mathrm{a}}$ & $10.72^{\mathrm{a}}$ & $10.18^{\mathrm{a}}$ \\
\hline
\end{tabular}

${ }^{\mathrm{a}} p<0.001,{ }^{\mathrm{b}} p<0.01,{ }^{c} p<0.05,{ }^{\mathrm{d}} p$ approached the significance $<0.05$. CD4 count $<200$ cells $/ \mathrm{mL}$ was not included because it was insignificantly associated with mental health summary scores $(p=0.407)$. Years since starting ART was excluded because of co-linearity with the variable, years since HIV diagnosis. *Further multivariable linear regression models were performed for each basic need, estimated coefficient $(\beta)$ unmet needs: food $=-4.10$, clothing $=-3.39$, housing cost $=-4.34$ or risk of homelessness $=-3.07$ (all, $p<0.001$ )
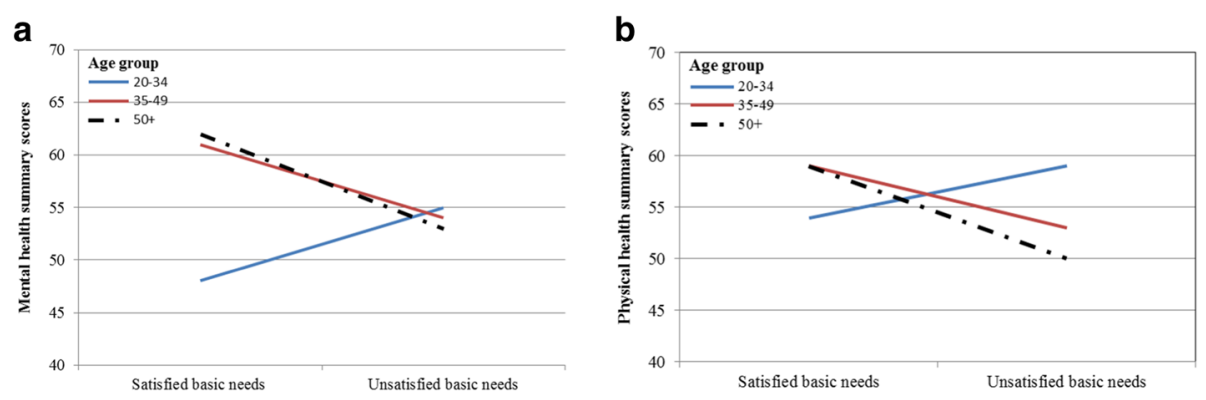

Fig. 2 Adjusted models of interaction terms between unmet basic needs and age groups $(N=496)$. a Multivariate regression model: The effect of unmet basic needs on physical health summary score was steeper in the oldest group than the middle-aged group $(F$ test $=4.72, p=0.009$, $\left.R^{2}=0.02\right)$. b Multivariate regression model: Mental health summary score was reduced by the effect of unmet basic needs, with the slope a bit steeper in the oldest group than in the middle-aged group ( $F$ test $=5.60, p=0.004, \mathrm{R}^{2}=0.02$ ) 
findings have health policy implications and offer insights into public health priorities targeting HIV-positive aging populations.

Our findings that the presence of unmet basic needs reduced mean physical health and mental health summary scores in the middle-aged and the oldest groups also have clinical importance. Studies have shown that the effect of age has a negative impact on physical health among HIV-positive populations [24, 46]. In our physical health summary model, when a basic need was not met, a decrement of 6- and 9-points in the middle-aged and the oldest groups, respectively, was observed. This is because the oldest group had significantly lower scores than the middle-aged group, and they were even lower than those of the youngest group, in all physical health subscales.

Studies have reported that age is associated with relatively good mental health quality of life [42, 47]. In our mental health summary model, when a basic need was not met, a decrement of 7- and 9- points was observed in the middle-aged and oldest groups, respectively. This suggests that the effect of unmet basic needs influences the mean mental health scores of the two older groups. The insignificant difference between satisfied and unsatisfied basic needs for mean scores of HRQoL in the younger group does not necessarily imply that unmet basic needs will not influence this group. Rather, as these participants age, their health may be expected to deteriorate should they continue to face unmet basic needs. Also, this group was relatively smaller compared to the middle-aged and the oldest groups.

There are some limitations to note in our study. A validated instrument for measuring basic needs would have improved our findings. It is also evident that, using cross-sectional data, we cannot infer a direct causal pathway between unmet basic needs and poor HRQoL but can only point out the association. In addition, because the sample participants were mostly individuals seeking services at community-based AIDS service organizations, our results may not generalize to all HIVpositive persons in Ontario or beyond. Our results, of course, rely on the accuracy of self-reporting on the part of the participants. We also did not control for depression. The scores for this variable would have correlated with all dimensional subscales, particularly with the mental health summary components. Thus, they would have biased the results in favour of our hypothesis.

\section{Conclusions}

The strength of our study is that it confirms the relationship between unmet basic needs and physical and mental health quality of life by age group, using reliable statistical tests. We recommend that future studies: 1) develop a valid instrument for measuring basic needs; 2) determine the causes of the high prevalence of unmet basic needs in this population beyond demographic and socioeconomic factors; 3 ) examine the longitudinal influence of unmet basic needs on HRQoL, using a variety of instruments, not only the MOS-HIV; and 4) determine the influence of unmet basic needs on comorbidities and life expectancy.

\section{Endnotes}

${ }^{1} \mathrm{RH}$ is being at risk of homelessness, inc is a personal gross income per month (Question 50), and mor is an amount rent or mortgage payment per month (Question 57).

\section{Acknowledgements}

The authors wish to thank the study participants for their continued participation and the community-based AIDS service organizations in Ontario for their sustained support of the Positive Spaces, Healthy Places Study.

\section{Funding}

The PSHP study is supported by grants from the Canadian Institutes of Health Research (CBR-75568 and CBR-94036), the Ontario Ministry of Health and Long-Term Care, the Ontario AIDS Network, the Wellesley Institute, and the Ontario HIV Treatment Network (CCB115). The funders had no role whatsoever in the design of the study nor the collection, analysis, and interpretation of data nor in the writing of the manuscript

\section{Availability of data and materials}

De-identified raw data and materials described in the manuscript are freely available from the corresponding author on reasonable request.

\section{Authors' contributions \\ PS created the concept of basic needs, designed the study, conducted the in-depth data analyses and wrote and revised the manuscript. SGr contributed substantially to data analyses. SBR, JG, TB and MVS contributed to the design of the study and provided important intellectual content and critical feedback. SGe, MS, JK, KH, SH, JW and GW contributed to the critical revision of the manuscript. All these authors read and approved the final manuscript and take public responsibility for the content. LVM was responsible for the Aboriginal arm of this study and played a key role in developing the questionnaire, analyzing the data, and presenting the findings. She brought to our team her life experiences as an Aboriginal woman and her passion to help Aboriginal people living with and at risk of HIV. She understood the critical role of housing in health and quality of life, and was a strong advocate for research to identify the housing needs of Aboriginal people in Ontario and for policy change that will lead to safe, stable housing for all. LVM passed away on December 1, 2010. This article is dedicated to her memory.}

\section{Ethics approval and consent to participate}

The study was approved by the Research Ethics Board at the University of Toronto (REB\#25710). All participants signed written consent forms.

\section{Consent for publication}

Not applicable.

Competing interests

The authors declare no competing interests.

\section{Publisher's Note}

Springer Nature remains neutral with regard to jurisdictional claims in published maps and institutional affiliations.

\section{Author details}

${ }^{1}$ Institute of Medical-Science, University of Toronto, Toronto, Canada. ${ }^{2}$ Baycrest Health Sciences, Toronto, Canada. ${ }^{3}$ Ontario HIV Treatment Network, Toronto, Canada. ${ }^{4}$ Ministry of Health and Long-Term Care, Toronto, Canada. ${ }^{5}$ School of Social Work, McMaster University, Hamilton, Canada. ${ }^{6}$ AIDS Thunder Bay, Thunder Bay, Canada. ${ }^{7}$ Bruce House, Ottawa, Canada. ${ }^{8}$ Ontario 
Aboriginal HIV/AIDS Strategy, Toronto, Canada. ${ }^{9}$ Fife House, Toronto, Canada. ${ }^{10}$ Centre for Urban Health Solutions, St. Michael's Hospital, Toronto, Canada. ${ }^{11}$ Positive Living Niagara, St. Catherine, Canada. ${ }^{12}$ Department of Psychiatry, University of Toronto, Toronto, Canada.

\section{Received: 14 June 2017 Accepted: 28 March 2018}

\section{Published online: 21 May 2018}

\section{References}

1. Cunningham WE, Andersen RM, Katz MH, Stein MD, Turner BJ, Crystal S, Zierler S, Kuromiya K, Morton SC, St CP, et al. The impact of competing subsistence needs and barriers on access to medical care for persons with human immunodeficiency virus receiving care in the United States. MedCare. 1999;37(12):1270-81.

2. Riley ED, Moore K, Sorensen JL, Tulsky JP, Bangsberg DR, Neilands TB. Basic subsistence needs and overall health among human immunodeficiency virus-infected homeless and unstably housed women. AmJEpidemiol. 2011; 174(5):515-22

3. Riley ED, Neilands TB, Moore K, Cohen J, Bangsberg DR, Havlir D. Social, Structural and Behavioral determinants of overall health status in a cohort of homeless and unstably housed HIV-infected men. PLoSOne. 2012;7(4): e35207.

4. Durbin A, Sirotich F, Antoniou T, Roesslein K, Durbin J, Lunsky Y. Unmet needs among men with human immunodeficiency virus in community mental health care: a cross-sectional study. AIDS Care. 2016;28(7):878-83.

5. Worthington C, Krentz HB. Socio-economic factors and health-related quality of life in adults living with HIV. IntJSTD AIDS. 2005;16(9):608-14.

6. Rueda S, Raboud J, Mustard C, Bayoumi A, Lavis JN, Rourke SB. Employment status is associated with both physical and mental health quality of life in people living with HIV. AIDS Care. 2011;23(4):435-43.

7. Briongos-Figuero LS, Bachiller-Luque P, Palacios-Martin T, De Luis-Roman D, Eiros-Bouza JM. Depression and health related quality of life among HIVinfected people. EurRevMedPharmacolSci. 2011;15(8):855-62.

8. Rourke SB, Bekele T, Tucker R, Greene S, Sobota M, Koornstra J, Monette L, Bacon J, Bhuiyan S, Rueda S, et al. Housing characteristics and their influence on health-related quality of life in persons living with HIV in Ontario, Canada: results from the positive spaces, healthy places study. AIDS \& Behavior. 2012;16(8):2361-73.

9. Choi SK, Fielden S, Globerman J, Koornstra JJ, Hambly K, Walker G, Sobota M, O'Brien-Teengs D, Watson J, Bekele T, et al. Food insufficiency, housing and health-related quality of life: results from the positive spaces, healthy places study. AIDS Care. 2015;27(9):1183-90.

10. Weiser SD, Tsai AC, Gupta R, Frongillo EA, Kawuma A, Senkungu J, Hunt PW, Emenyonu NI, Mattson JE, Martin JN, et al. Food insecurity is associated with morbidity and patterns of healthcare utilization among HIV-infected individuals in a resource-poor setting. AIDS. 2012;26(1):67-75.

11. Pitts M, Grierson J, Misson S. Growing older with HIV: a study of health, social and economic circumstances for people living with HIV in Australia over the age of 50 years. AIDS PatientCare STDS. 2005;19(7):460-5.

12. Heckman TG, Heckman BD, Kochman A, Sikkema KJ, Suhr J, Goodkin K. Psychological symptoms among persons 50 years of age and older living with HIV disease. Aging MentHealth. 2002;6(2):121-8.

13. Millar BM, Starks TJ, Gurung S, Parsons JT. The impact of comorbidities, depression, and substance use problems on quality of life among older adults living with HIV. AIDS Behav. 2017;21(6):1684-90.

14. Hessol NA, Zepf R, Zobell E, Weiser SD, John MD. Food insecurity and aging outcomes in older adults living with HIV. AIDS Behav. 2017;21(12):3506-14.

15. Brennan DJ, Emlet CA, Brennenstuhl S, Rueda S. Socio-demographic profile of older adults with HIV/AIDS: gender and sexual orientation differences. CanJAging. 2013;32(1):31-43.

16. Illa L, Brickman A, Saint-Jean G, Echenique M, Metsch L, Eisdorfer C, Bustamante-Avellaneda V, Sanchez-Martinez M. Sexual risk behaviors in late middle age and older HIV seropositive adults. AIDS Behav. 2008; 12(6):935-42.

17. Kwiatkowski CF, Booth RE. HIV risk behaviors among older American drug users. JAcquirlmmuneDeficSyndr. 2003;33(Suppl 2):S131-7.

18. Justice AC, McGinnis KA, Atkinson JH, Heaton RK, Young C, Sadek J, Madenwald T, Becker JT, Conigliaro J, Brown ST, et al. Psychiatric and neurocognitive disorders among HIV-positive and negative veterans in care: veterans aging cohort five-site study. AIDS. 2004;18(Suppl 1):S49-59.
19. Guaraldi G, Orlando G, Zona S, Menozzi M, Carli F, Garlassi E, Berti A, Rossi E, Roverato A, Palella F. Premature age-related comorbidities among HIVinfected persons compared with the general population. ClinInfectDis. 2011; 53(11):1120-6.

20. Desquilbet $L$, Jacobson $L P$, Fried $L P$, Phair JP, Jamieson $B D$, Holloway $M$, Margolick JB. HIV-1 infection is associated with an earlier occurrence of a phenotype related to frailty. JGerontolA BiolSciMedSci. 2007;62(11):1279-86.

21. Oursler KK, Goulet IL, Crystal S, Justice AC, Crothers K, Butt AA, RodriguezBarradas MC, Favors K, Leaf D, Katzel LI, et al. Association of age and comorbidity with physical function in HIV-infected and uninfected patients: results from the veterans aging cohort study. AIDS PatientCare STDS. 2011; 25(1):13-20.

22. Marcus $J \mathrm{~L}$, Chao CR, Leyden WA, Xu L, Quesenberry CP Jr, Klein DB, Towner WJ, Horberg MA, Silverberg MJ. Narrowing the gap in life expectancy between HIV-infected and HIV-uninfected individuals with access to care. Journal of acquired immune deficiency syndromes (1999). 2016;73(1):39-46.

23. Walters SJ, Munro JF, Brazier JE. Using the SF-36 with older adults: a crosssectional community-based survey. Age Ageing. 2001;30(4):337-43.

24. Piette J, Wachtel TJ, Mor V, Mayer K. The impact of age on the quality of life in persons with HIV infection. JAging Health. 1995;7(2):163-78.

25. Canadian definition of homelessness. Homeless Hub 10 years: Homelessness 101. 2012. Retrived from: http://homelesshub.ca/about-homelessness/ homelessness-101/causes-homelessness. Accessed 21 Apr 2018.

26. Santos JR. Cronbach's Alpha: A tool for assessing the Reliability of Scales. Extension J Inc. 1999;37(2). Retrieved from https://www.joe.org/joe/ 1999april/tt3.php.

27. Tavakol M, Dennick R. Making sense of Cronbach's alpha. Int J Med Educ. 2011;2:53-5. Retrieved from: www.ijme.net/archive/2/cronbachs-alpha.pdf.

28. Wu AW, Revicki DA, Jacobson D, Malitz FE. Evidence for reliability, validity and usefulness of the medical outcomes study HIV health survey (MOS-HIV). Quallife Res. 1997;6(6):481-93.

29. Cohen JM, Whittaker E, Walters S, Lyall H, Tudor-Williams G, Kampmann B. Presentation, diagnosis and management of tuberculosis in HIV-infected children in the UK. HIVMed. 2008;9(5):277-84.

30. Medical Outcome Study-HIV Health Survey (MOS-HIV). https://eprovide. mapi-trust.org/instruments/medical-outcome-study-hiv-health-survey. Accessed 21 Apr 2018.

31. MOS-HIV Health Survey (1996). Users Manual. Retrieved from: http://www. ibrarian.net/navon/page.jsp?paperid=16209358\&searchTerm=mos-hiv. Accessed 21 Apr 2018

32. Revicki DA, Sorensen S, Wu AW. Reliability and validity of physical and mental health summary scores from the medical outcomes study HIV health survey. MedCare. 1998;36(2):126-37.

33. Blanco JR, Jarrin I, Vallejo M, Berenguer J, Solera C, Rubio R, Pulido F, Asensi $\mathrm{V}$, Del AJ, Moreno S. Definition of advanced age in HIV infection: looking for an age cut-off. AIDS ResHumRetroviruses. 2012;28(9):1000-6.

34. Sherbourne CD, Stewart AL. The MOS social support survey. SocSciMed. 1991;32(6):705-14

35. Walker GA, Shostak J. In: Common Statisticel methods for clinical research with SAS* examples, Third Edition Cary,: SAS Institute Inc. edn.; 2010: Chapter10: Linear regression. p.191-219.

36. Hofmann DA. An overview of the logic and rationale of hierarchical linear models. J Manag. 1997;23(6):723-44.

37. Fraizer $\mathrm{P}$, Barron $\mathrm{K}$, Tix $\mathrm{A}$. Testing moderator and mediator effects in counseling psychology research. JCounsPsychol. 2004;51:115-34.

38. Emlet CA. Truth and consequences: a qualitative exploration of HIV disclosure in older adults. AIDS Care. 2008;20(6):710-7.

39. Joyce GF, Goldman DP, Leibowitz AA, Alpert A, Bao Y. A socioeconomic profile of older adults with HIV. JHealth Care Poor Underserved. 2005;16(1): 19-28.

40. Hinkin $\mathrm{CH}$, Hardy DJ, Mason Kl, Castellon SA, Durvasula RS, Lam MN, Stefaniak M. Medication adherence in HIV-infected adults: effect of patient age, cognitive status, and substance abuse. AIDS. 2004;18(Suppl 1):S19-25.

41. Greenbaum AH, Wilson LE, Keruly JC, Moore RD, Gebo KA. Effect of age and HAART regimen on clinical response in an urban cohort of HIV-infected individuals. AIDS. 2008;22(17):2331-9.

42. McGowan J, Sherr L, Rodger A, Fisher M, Miners A, Johnson M, Elford J, Collins S, Hart G, Phillips A, et al. Effects of age on symptom burden, mental health and quality of life amongst people with HIV in the UK. J Int AIDS Soc. 2014;17(4 Suppl 3):19511. 
43. Fang X, Vincent W, Calabrese SK, Heckman TG, Sikkema K, Humphries DL, Hansen NB. Resilience, stress, and life quality in older adults living with HIV/ AIDS. Aging Ment Health. 2015;19(11):1015-21.

44. Kahana E, Kahana B. Successful aging among people with HIV/AIDS. JClinEpidemiol. 2001;54(Suppl 1):S53-6.

45. Vance DE, McGuinness T, Musgrove K, Orel NA, Fazeli PL. Successful aging and the epidemiology of HIV. ClinIntervAging. 2011;6:181-92.

46. Nokes KM, Holzemer WL, Corless IB, Bakken Z, Brown MA, Powell-Cope GM, Inouye J, Tuset $\mathrm{M}$. Health-related quality of life in persons younger and older than 50 who are living with HIV/AIDS. Research on Aging. 2000;

47. George S, Bergin C, Clarke S, Courtney G, Codd MB. Health-related quality of life and associated factors in people with HIV: an Irish cohort study. Health Qual Life Outcomes. 2016;14(1):115.

Submit your next manuscript to BioMed Central and we will help you at every step:

- We accept pre-submission inquiries

- Our selector tool helps you to find the most relevant journal

- We provide round the clock customer support

- Convenient online submission

- Thorough peer review

- Inclusion in PubMed and all major indexing services

- Maximum visibility for your research

Submit your manuscript at www.biomedcentral.com/submit
Biomed Central 